\title{
Using a Categorisation Structure to Understand Interaction in Children's Books
}

\author{
Claire Timpany, University of Waikato, New Zealand \\ Nicholas Vanderschantz, University of Waikato, New Zealand
}

\begin{abstract}
Children's books can vary greatly in the type of and depth of interaction that is required from the reader. The types of interaction demanded by different types of books can be explored using contrasting paradigms. Previously Timpany \& Vanderschantz (2012) proposed a categorisation of interactive children's books that used two continuums that took into consideration Physical Enhancement and Content Sequencing. This paper looks at those categorisations made by Timpany \& Vanderschantz (2012) and considers how the multitude of formats addresses either the physical or intellectual aspects of children's reading and how this then may be used to engage the reader. To do this, a database of 132 books was audited to assess the interactivity of these books against those categorisation systems. The range of books surveyed is discussed in terms of what methods are used to create the interaction within each of the interactivity levels and across types of books. Findings from this audit demonstrate interesting interactions between age, physical enhancement versus content sequencing, and the relationship of these to mechanisms for interactivity such as paper engineering, illustration and story structure. The majority of the books in the sample have no interactive qualities on one of the two-categorisation scales. Physically enhanced books were marginally more highly represented on the scale at higher levels of interactivity. Counter intuitively, the physically interactive pop up books were seen to fall predominantly in lower categories (1 or 2) for physical enhancement, while books requiring image search, an intellectual activity, were also predominantly in the lower categories (1 or 2) for content sequencing.
\end{abstract}

Keywords: Books, Interactive Books, Children's Reading, Interactivity

\section{Introduction}

$\mathrm{T}$

The physical book is still widely used as a medium for children's reading, especially in the early years. This research was motivated by a lack of understanding in the literature about what types of interactivity our children are encountering in their reading material and how this interactivity might be influencing their experiences. Although the level of interaction provided by some books can seem limited to just turning a page, even simple tasks like these can assist a child in developing motor skills, hand-eye coordination and even learning about textures. Simple types of interaction like turning the page of a book are termed "lightweight". They are types of interaction that obtain little thought or effort from the reader and those that the reader is unlikely to recall later (Marshall and Bly 2005). The idea of incorporating interactivity into printed books for children opens up an opportunity for the reader to become more engaged in the literacy experience and gain much more from the book depending on the level of interactivity that it involves.

Previously Timpany \& Vanderschantz (2012) proposed a categorisation of interactive children's books that used two continuums that take into consideration Physical Enhancement and Content Sequencing. This paper looks at those categorisations made by Timpany \& Vanderschantz (2012) and considers how the multitude of interactive printed book formats addresses either the physical or intellectual aspects of children's reading and how this then may be used to engage the reader. We used that system to categorise and analyse a set of 132 books and in so doing have started to consider in more depth the implications of the categorisation of children's interactive books.

As with our previous work, the purpose of this research was to develop an understanding of the types of interactive print books that are available for children. Our previous study considered what features are provided in books to encourage interactions from the reader and in so doing we

The International Journal of the Book

Volume 10, 2013, www.booksandpublishing.com, ISSN 1447-9516

(c) Common Ground, Claire Timpany, Nicholas Vanderschantz, All Rights Reserved

Permissions: cg-support@commongroundpublishing.com 
developed a classification system for discussing interactivity in printed books. We will use this system to investigate a sample of children's interactive books and analyse where on our continuum these books fall. From this we will be able to see what trends are present in the design of children's interactive books.

While the degree of interaction encouraged by features within books is being assessed, the benefits of these degrees or levels of interactivity are not being assessed within this paper. The primary concern in this research was the interactions of the reader or readers that were directly motivated by the content of the book. That is, not interactions that a parent or teacher might instigate with the child during the act of reading. Future work in this area will subsequently lead to an understanding of the degree of interactivity that these features facilitate.

\section{Related Work}

\section{Children's Books Design}

In an experiment by Carter (1988), in which children were given the opportunity to choose their own reading material, book characteristics such as the structural elements, title and illustration where shown to have an influence on children's selection of reading material. Book characteristics, such as cover or illustration and typography often affect children's choice as these commonly depict what the book will be about. In Carters' (1988) study, children often chose a book for the following reasons, they were familiar with the author, they wanted to improve a skill, the book belonged to a series, or they believed it had content which interested them, as observed by scanning illustrations or the title and cover of the book. This study shows the importance children place on the acts of scanning internal content such as illustrations, as well as external features such as titles and covers for book selection. This indicates there is potential for the design and features of interactive books to influence book selection.

Phinney and Colabucci (2010) argued that in picture books, typography performs a vital and complex role in expressing meaning. In children's illustrated books the manipulation of the typesetting and the selection and design of the typeface can be a useful aesthetic tool (Phinney and Colabucci 2010; Thiessen and Dyson 2009).

Expressive typography is a newer concept that accentuates aspects of the typography. It thus enables the typography to become part of the visual experience children have when reading picture books. It examines the layout of the typography through size variations and type on a path. It also employs different design features of typography (i.e. capitals, bold, italics) as a way to place emphasis on specific parts of the body copy (Phinney and Colabucci 2010). In so doing, children's attention can be focussed on a particular area of the visual information which will result in expanding the children's comprehension of the text (Watts et al. 1974).

Illustrations in children's picture books are used to develop or extend the plot, define and develop characters, and establish the setting and mood of a story (Brookshire, Scharff, and Moses 2002). Illustrations are also used to develop and increase the reader's comprehension. This is done through the expansion of children's vocabulary through concrete visual examples of complex ideas within plot or character descriptions and in so doing helps children form concepts about the world around them (Brookshire, Scharff, and Moses 2002). It can therefore be hypothesised that enhanced illustrations that incorporate either physical or intellectual interactions or design features will also operate in such a way to focus, enhance and strengthen learning for a young reader.

Thiessen and Dyson (2009) discuss research regarding the view that illustrations are too distracting to new readers as it removes their attention from the verbal information. However, an alternative view in the literature, for example Brookshire et al. (2002) and Schallert (1980), is that illustrations are important to the development of literacy skills in new readers. Illustrations are useful in assisting with the meaning of the texts. It is important to note however, that this happens when illustrations support and illustrate the writing rather than creating an untrue or misrepresented artistic interpretation of it (Nodelman 1990). Thiessen and Dyson (2009) 
concluded that this is due to the fact that pictures can help children understand the unknown words in the text, or express further information that cannot be included in the text.

Brookshire et al. (2002) and Schallert (1980) both suggest that in presenting illustrations vividly, compactly and clearly they will portray the author's message to the reader more simply. This further emphasises the point that Nodelman (1990) made, that illustrations "must provide visual information that supports the verbal information” (p. 82).

\section{Types of Interactivity}

Definitions of interactivity often differ greatly depending on the context, the purpose of the definition and the medium or technology where the interaction is occurring. "Communicative interaction concerns things which could achieve changes of state in the mental world" (ElsomCook 2001, 9). The principles of context and structure are important in creating interactive environments where users can efficiently achieve their intended goals, whether these are physical or communicative interactions.

Use of the term interaction is often closely tied to technology, but is also an important factor in communication. Because of these different approaches there is often conflicting definitions of interactivity and what it entails. When we consider interactivity in children's books it is both the artifact and the content with which the reader is interacting. When defining interactivity at its most basic level, irrespective of media, meaning can be broken down as; "[T]he prefix 'inter' means 'between or among' and 'act' is defined as the process of doing or performing something" (Spence 2007, p.141). This implies that interaction can occur in both a physical or an intellectual environment. Spence (2007) considers that there are three modes of interaction; continuous, stepped and passive, but also acknowledges that many systems require more than one mode of interaction, and calls this integration composite interaction. Continuous interaction occurs through a continuous functional relationship, stepped interaction involves discrete actions that provoke a response and passive interaction occurs within the viewer in response to external sensory factors resulting in cognitive processing.

In our previous work (Timpany and Vanderschantz 2012) we discussed how researchers have attempted to define levels of interactivity with different focuses. For example Lander states, "interaction can occur at different levels and in different ways" (Lander 1999, p.1). Bongers \& Veer (2007), Jensen (1998) and Sims (1994) discuss interactivity as a continuum rather than a discrete or binary presence or lack of. The work of these researchers was used as a starting point for the development of our method for the classification of children's interactive books.

\section{Methodology}

Using the levels of interactivity determined by Timpany and Vanderschantz (2012) the current research analysed the findings from a survey of 132 interactive children's books. This survey audited three publicly funded libraries, a publicly funded kindergarten and a publicly funded intermediate school library as well as two private collections in New Zealand during the period of December 2010 through February 2011.

The researchers enlisted the expertise of librarians and teachers at these institutions to uncover the interactive children's books that were available in each of these collections. Librarians and teachers were encouraged to identify books that included both commonly considered interactive book types (ie. choose your own adventure and pop-up), but also books that included puzzles, books with instruction for game play or making and doing outside of the book, and unusual formats, printing or binding techniques.

As previously discussed, the central purpose of this investigation was to further understand interaction and the use and types of interaction in children's printed books, therefore, no prejudgement of the level of interactivity was considered by the researcher when collecting books for the audit. 
The analysis looked at the two scales of interactivity that were defined through previous research (Timpany and Vanderschantz 2012) and sought to develop a greater understanding of the distribution methods of interaction used within the survey sample and the types of books that fell into different levels of the two scales. The two continuum that were developed in this previous study are as follows:

\begin{tabular}{|l|}
\hline Physical Enhancement \\
\hline$\underline{\text { Level } 0}$ - Reader is required to open \\
book and turn pages \\
\hline $\begin{array}{l}\text { Level } 1 \text { - Reader is required to open } \\
\text { book and turn pages with some } \\
\text { additional interaction with the book }\end{array}$ \\
\hline $\begin{array}{l}\text { Level } 2 \\
\text { additional inner pages to reveal further } \\
\text { content }\end{array}$ \\
\hline $\begin{array}{l}\text { Level } 3 \\
\text { turn wheels, Rull tabs, push buttons etc. }\end{array}$ \\
\hline $\begin{array}{l}\text { Level } 4 \text { - Reader is required to interact } \\
\text { with multiple layers of interactive } \\
\text { elements or create/arrange content } \\
\text { themselves }\end{array}$ \\
\hline
\end{tabular}

\begin{tabular}{|l|}
\hline Content Sequencing \\
\hline $\begin{array}{l}\text { Level } 0 \\
\text { through page content }\end{array}$ \\
\hline $\begin{array}{l}\text { Level } 1 \text { - Reader's attention is intentionally guided in a } \\
\text { non-linear course around page content }\end{array}$ \\
\hline $\begin{array}{l}\text { Level } 2 \\
\text { course around page/book content and drawn back and } \\
\text { forth between set areas of contrasting content }\end{array}$ \\
\hline $\begin{array}{l}\text { Level } 3 \\
\text { to/or determine the order in which the pages are read }\end{array}$ \\
\hline $\begin{array}{l}\text { Level } 4 \\
\text { book by } \text { - Reader is required to progress through the } \\
\text { story line }\end{array}$ \\
\hline $\begin{array}{l}\text { Level } 5 \\
\text { actions guided by conions that will affect the ultimate }\end{array}$ \\
\hline
\end{tabular}

We categorised each of the books collected using the system developed, with each book being placed onto the two scales of interactivity. We placed books within the continuum as described in our previous work, "when identifying where a book will fall within this system a user would first define at which step on the Physical Enhancement scale a book falls and then which step of the Content Sequencing scale a book falls” (Timpany and Vanderschantz 2012).

\section{Results}

The database recorded information on many aspects of the books. Data collected included publisher, publication year, and number of pages as well as whether it was fiction or non-fiction and hardback or softcover. The majority of books were; published since the mid-1990's, fiction (90\%), hardback (74\%) and between 10 and 40 pages, with the median being 24 pages.

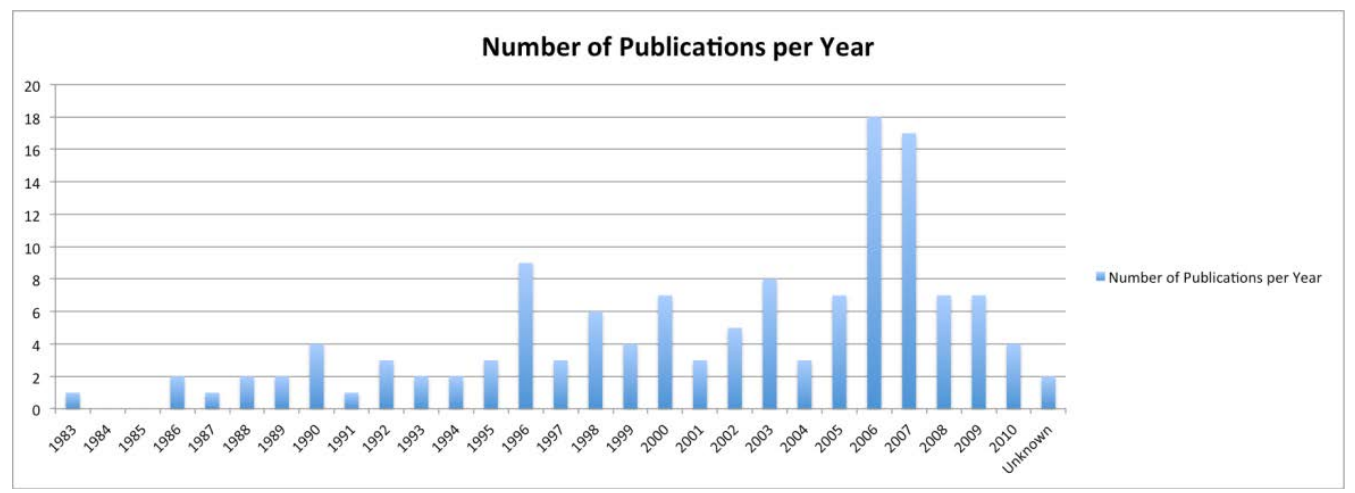

Figure 1: Publication year for sampled books 
It is also important to note that different books are designed so that they are appropriate for different age groups. This is recognised very clearly and accurately by Wheelers (http://www.wheelers.co.nz/), a website database of books that are available for purchase in New Zealand. This website is used by book buyers commercially and for use within New Zealand schools and contains an extensive collection of books that have been classified under two categories; 'Interest Age' and 'Reading Age'. This categorisation system based on age groups proved to be a very useful resource when creating the database of books for this research. Each book that is recorded in the database was searched for on the Wheelers website and the relevant Interest Age and Reading Age were recorded alongside each book that was found in the Wheelers system. Twenty five of the 135 books in our sample were not available in the Wheelers system and 12 were classified by Wheelers as All Ages.

The majority of books in our sample were aimed at a reading and an interest age of between 3 and 8 years. Though the sample extended from books aimed at 0 to 17 year olds, all but two books had a reading age within the range of 0 to 12 years, other than those that were classified as "Unknown" or were for "All Ages". Several of the books had reading ages and interest ages that were different to each other; this was the case for 11 of the books. The majority of these books had a reading age higher than the interest age, with one book having a reading age that was broader than the interest age. Figure 2 below shows how many books are available at each age for both of the Wheelers categorisations of Reading and Interest age. A user can read this graph as indicating that there are, for example, 78 books in our sample that were suitable at the reading and interest ages of 5 year olds, and 72 and 73 books respectively for reading and interest ages of 4 year olds. That is to say that should a book be available to be used for $0-4$ year olds it would appear once in each of the columns from 0-4 of Figure 2. At this stage a detailed analysis of age data is outside the scope of this study and will be investigated in future research.

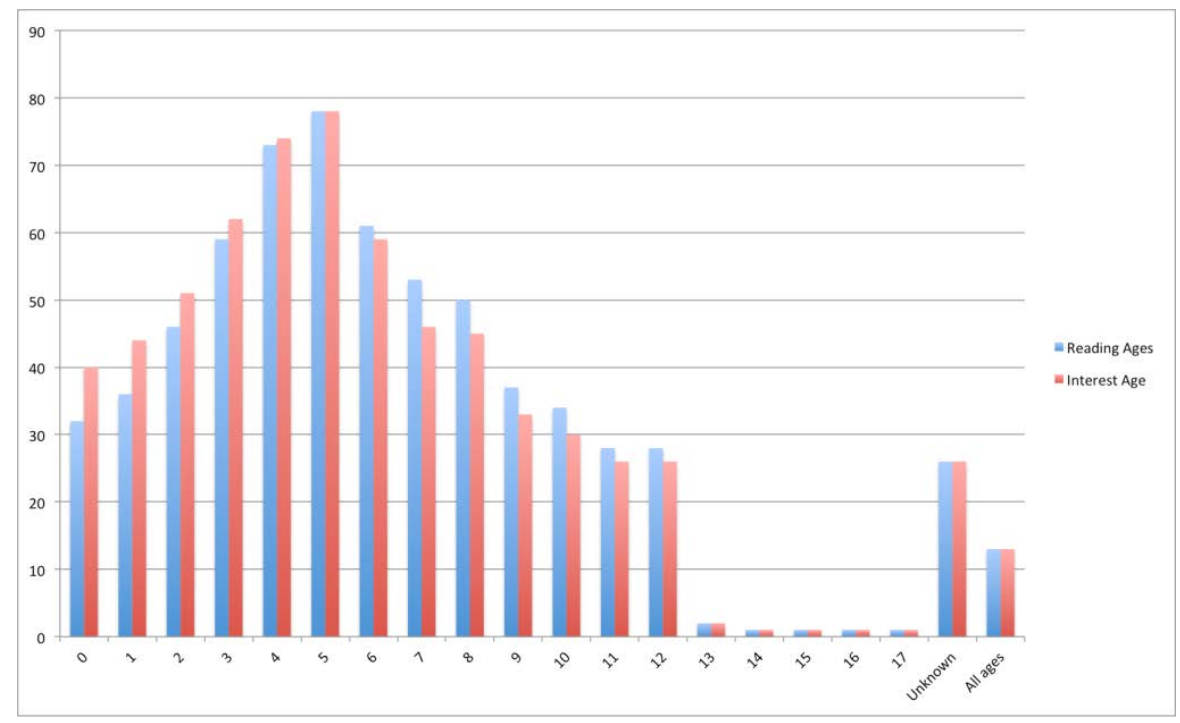

Figure 2: Reading Age versus Interest Age

These bibliographic findings (of publication date, reading and interest age) give a valid picture of the sample of this study and provide some insight into the related features of the books that the curators of this sample considered interactive. We have not analysed in this paper in any further detail the interactions of these bibliographic features of these books with relationship to our classification system, however this is of potential future interest.

\section{Levels of Interaction in the Sample}

The graph below shows the distribution of books across the levels of interactivity according to the categorisation system developed by Timpany and Vanderschantz (2012). The majority of the 
sample was at Levels 0 and 1 with many books also at Level 2 on the Content Sequence (CS) scale and a large number at Level 3 on the Physical Enhancement (PE) scale. The five categories that had the greatest number of books in them were those at Level 0 on one scale or the other. This survey turned up no books that were high on both scales of interactivity, though these may exist, they were not identified in this sample of 132 books.

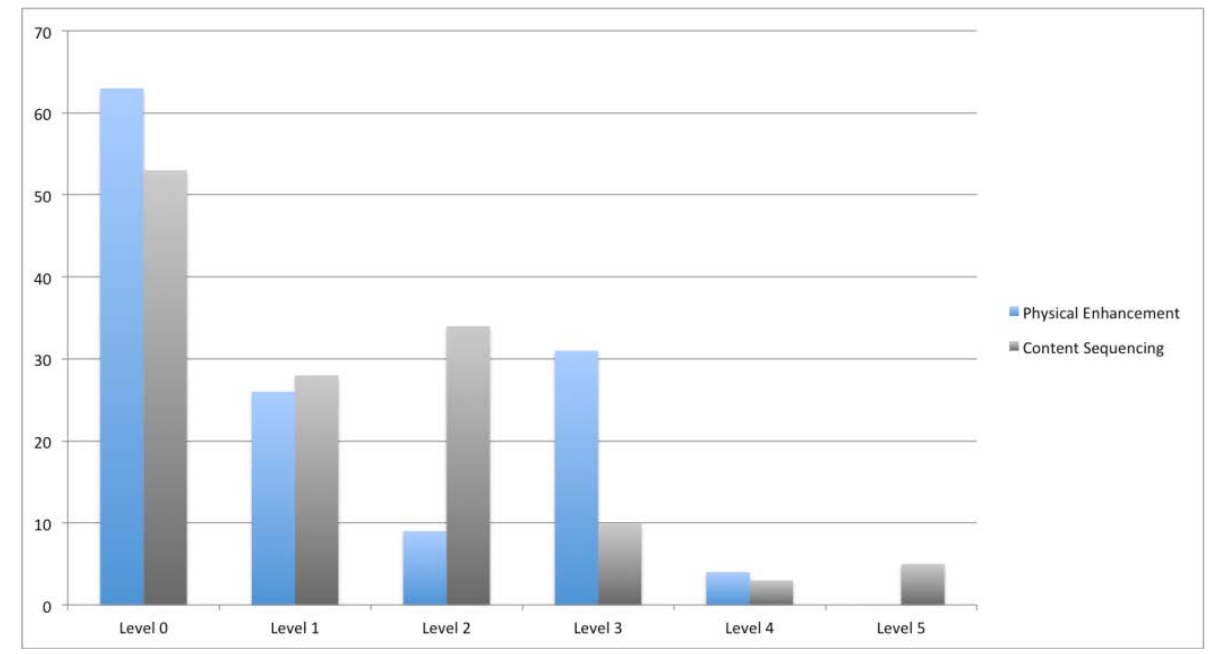

Figure 3: Distribution of books at interaction levels

The majority of books in the sample were between Levels 0 and 3 on one or both of the scales of interactivity defined by Timpany and Vanderschantz (2012).

On the scale of interaction, most books were low and usually created their interaction through either physical enhancement or through content sequencing. Sixty-three books had no interaction on the scale of Physical Enhancement and 53 books had no interaction on the scale of Content Sequencing. Only 32 of the books in our sample incorporate interactive elements that created both physical interaction as well as interactions through the sequencing of content. In other words it is not common for both continuum to be engaged by a designer when developing interactive children's books, typically a book will fall on either the physically enhanced continuum or the content sequencing continuum.

In many of the books that were considered linear or a Level 0 in terms of their interactivity the interaction occurred at an intellectual level rather than at a physical level. Consequently the 'curators' (librarians, teachers, books owners as described in the methodology section of this paper) of the sampled collections considered them to be 'interactive books' worthy of consideration in this investigation.

The shift in balance at levels 2 and 3 is particularly interesting. Remembering that the physical engagement scale ends at 4 . The physical enhancement of books tapers off from 0 , other than a sharp spike at Level 3. This spike could be attributed to the significant number of lift flap books, categorised at Level 3, that were found within the sample. The rise in book numbers at Level 2 on the content sequencing scale is likely attributed to the large number of searching illustration type books within the sample, many of these being categorised at a content sequencing Level 2.

\section{Discussion}

There were two main methods of interaction observed within the sample. Physical, where the interaction is intentionally facilitated through the physical form of the book, for example lifting flaps. Intellectual, where the reader interacts by thinking about the material presented, for example, solving problems. The majority of interaction modes observed within the children's books surveyed fall into one or more of the three modes outlined by Spence (2007), stepped, 
passive and continuous. Interactions within children's books were generally stepped or passive interaction. The passive interactions occurred mostly in books that used content sequencing (or intellectual interaction) as a means of interaction. Books that used physical enhancement (or physical interaction) as their means of interaction generally employed stepped interaction rather than continuous.

\section{Book Interaction Type}

When looking at the sample of 132 books we found that there were commonly occurring types of book interactions or methods for creating the interaction within the book. Distribution within the levels of interactivity can be partly explained by the types of interactivity found within the books that were present in the sample. There were a total of sixteen different book interaction types identified within our sample, these included; enhanced illustrations, expressive typography, graphic novel, searching illustration, choose story path, movable elements, lift flaps, and splitpage.

These interactions were identified as being present in a book whether they appeared on every page or a single page within a book. Thus a book identified as having enhanced illustrations may have simply had a single illustration within a multi-page illustrated book that contained an overgloss, a tactile printed ink or an alternative material or textile glued into the illustration. Equally a book may have been classified to include questions if these were present only on the final page of the book.

In the analysis of our sample the most interesting finding was the split between the types of interaction (physical or intellectual) within the books. That is, interactions where the physical format of the book encouraged the reader to interact with the physical form of the book in some way (shown grey in Figure 4 below), compared to books where the reader was encouraged to interact within the mind (shown blue in Figure 4 below). The sample was reasonably well balanced between Physical (85) and Intellectual (79) books.

Figure 4 below shows how the type of interactivity within books was distributed within the sample. The most commonly occurring type of book interaction was the searching illustration book, an intellectual interaction category for books, with 24 instances identified within the sample. The next most commonly occurring type of interactivity within books was the movable elements book, a physical interaction category book, with 17 instances.

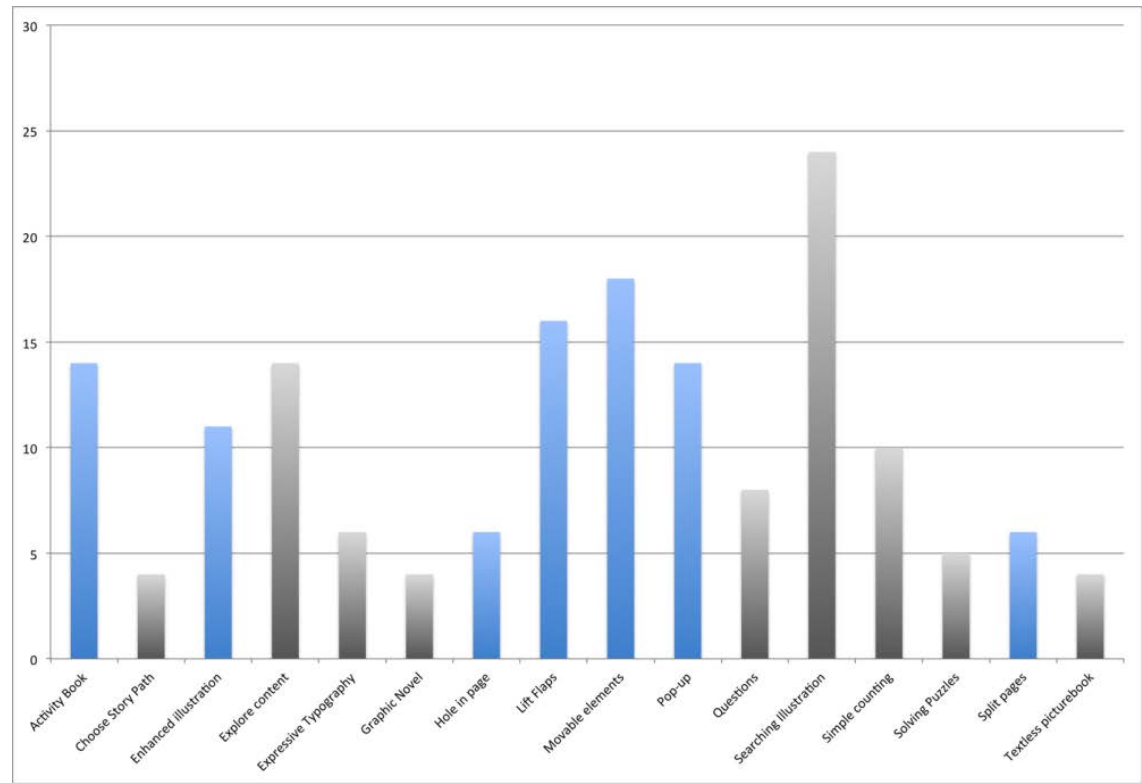

Figure 4: Book interaction types identified in our sample. 
To assess where on the continuum books in our sample fell we considered books within the physical enhancement continuum separately from books within the content sequencing continuum. For ease of assessment we have separated the books into the two classifications of book that we were able to identify - Physical Interaction and Intellectual Interaction. This can be seen in Figure 5 below.

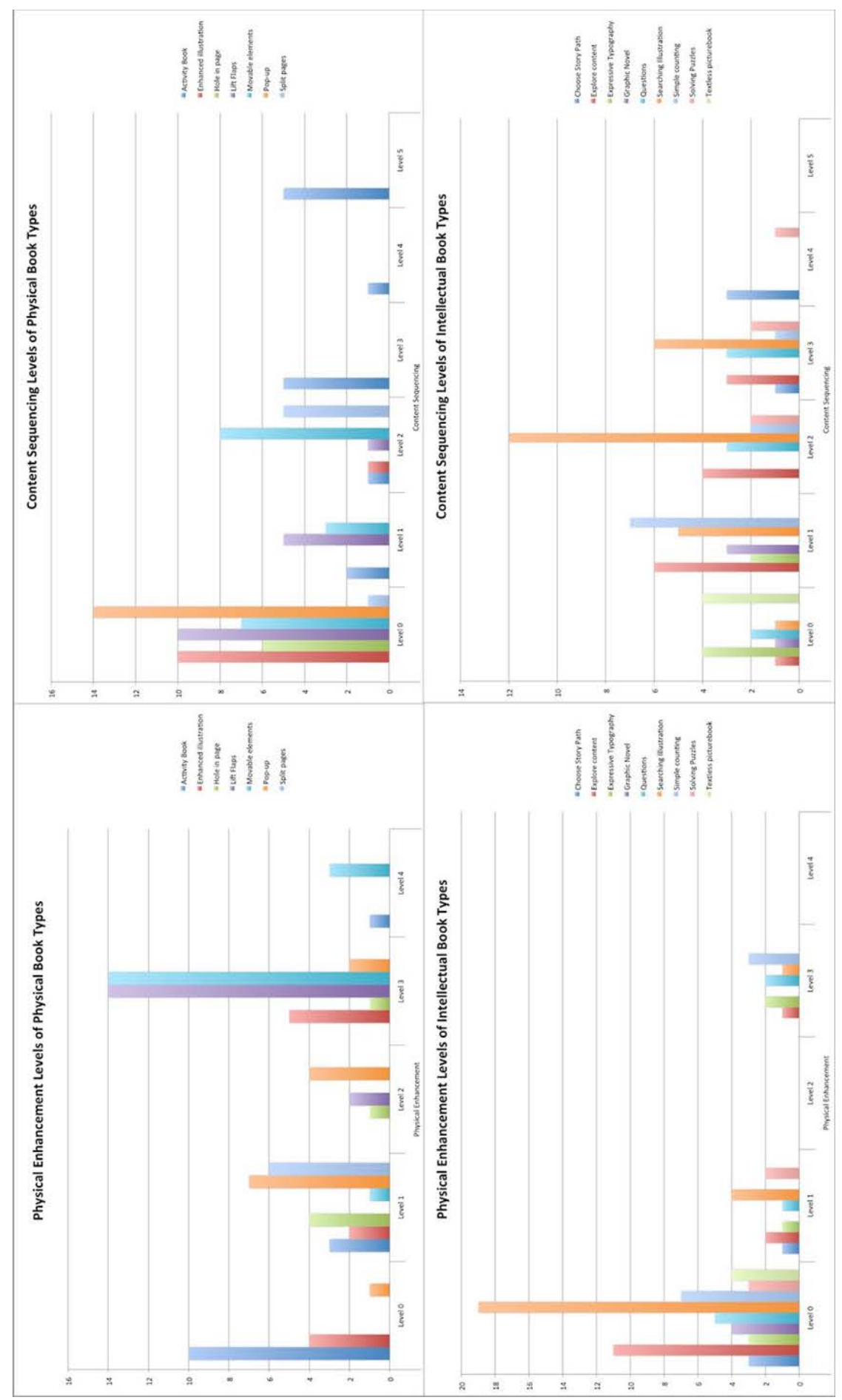

Figure 5: Books according to their placement within our continuum 
As can be seen in Figure 5 above, the spread of Physical Interaction Book Types on the Physical Enhancement scale is fairly well distributed with a spike at Level 3 on this scale. In contrast, Intellectual Interaction Book Types are much more likely to be crowded to the lower end of this Physical Enhancement Scale. This is contrasted on the Content Sequencing Scales with Intellectual Book Types being fairly spread with Physical Book Types being crowded in the Levels 0,1 and 2.

Thirty-five of the 132 books sampled employed more than one of our identified types of book interaction. Most of these 35 books combined two interactive book types, with just 3 books using three interactive book types and one book utilising four interactive book types. The only interactive book types not to appear combined with another were Graphic Novel and Textless Picturebook. The book type most commonly used in combination with another was Lift-flaps (11), followed by Searching Illustration (9), Activity Book (7) and Explore Content (7). The most frequent combinations of interactive book types were Explore Content with Activity Book, and Searching Illustration with Solving Puzzles. The one book that incorporated four interactive book types together combined Activity Book, Explore Content, Searching Illustration and Questions interactive book types.

Of the books that contained more than one type of interaction, eighteen had both a physical and an intellectual interaction type. The most commonly occurring book interaction type was an activity book, with seven of these 18 books using the activity book interaction type; explore content and lift-flaps books were the next most commonly represented in this sample with five books having this type of interaction. The most common combination of interaction types was found in books that created interaction as both an activity book and also prompted the reader to explore content (4). Interestingly however, only half of the eighteen books that had both physical and intellectual interactive book types were above a Level 0 on both the Content Sequencing and the Physical Enhancement scales.

Additionally, 15 of the 132 books were categorised as a Level 0 on both the Physical Enhancement scale and the Content Sequencing scale. These were often book types that required intellectual interaction, however this did not mean that they had content sequencing interactions. These books were often textless picture books or books that incorporated expressive typography.

When considering the book interaction types in relation to the Content Sequencing scale, not all of the types of the intellectual interaction were above a zero on the scale. It is also apparent that book interaction types do not tend to fall into a single level of the scales - similar books will fall into different positions on the scale due to the different use of a particular interactive feature. ie. a movable element in one book may be used in a particular way that makes it more physically enhanced than in another movable element book.

Four interactive book types were identified within the sample as having more than one instance where they scored at a Level 1 or higher on both scales. The interactive book types that were identified to score highly on both scales were: Activity Book (2), Explore Content (1), Lift Flap (4), Movable Elements (8), Searching Illustration (1) and Split Pages (5). All of the book types that scored highly on both scales were physically interactive book types. This seems to suggest that Searching Illustration, Movable Elements and Lift Flap interactive book types can be successfully used for instigation of both content sequencing and physical interaction. This of course is not to say that all Movable Elements or Split Pages books (for example) were identified as performing highly on both scales. Physical interaction types had a higher instance of creating interaction on both scales were predominantly physical book interaction types. Physical interaction types are more likely to appear on both scales or likely to be able to be used for PE and CS. The only two intellectual book types to appear on both scales were 1 searching illustration book and 1 explore content book.

\section{Most Commonly Occurring Book Interaction Types}

We now consider in detail the six types of books that occurred most commonly within the sample. Of the most common book types, four were physical interaction types and two were 
intellectual interaction types. The four most commonly occurring book types classified as physical interaction books were those we termed Movable Elements, Lift Flaps, Pop-up and Activity books. For those classified as intellectual interaction books the most commonly occurring book types were Searching Illustration and Exploring content books.

\section{Movable Elements (a physical interaction type of book)}

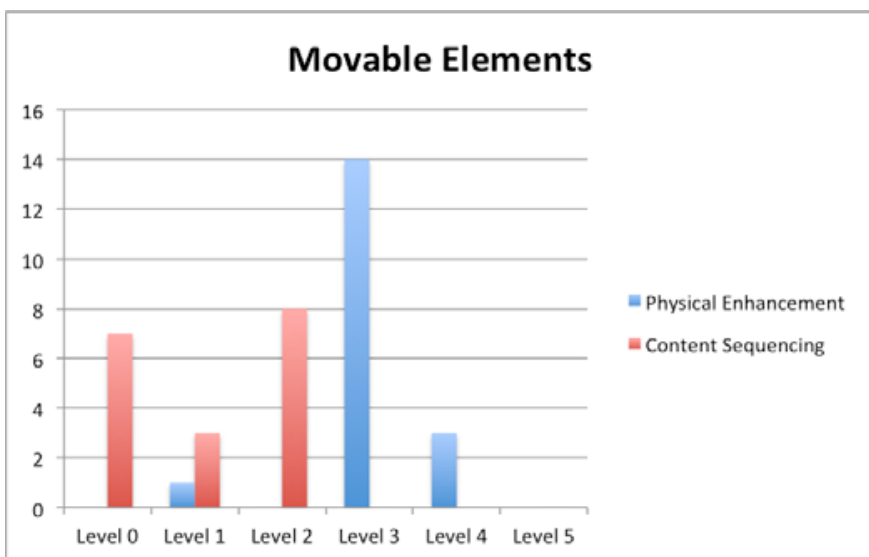

Figure 6: How Movable Elements books were classified according to the Timpany and Vanderschantz method

In our sample we found 18 Movable Elements books. These types of books typically fell into the Physical Enhancement scale in the following way:

Level 3 - Reader is required to lift flaps, turn wheels, pull tabs, push buttons etc.

Level 4 - Reader is required to interact with multiple layers of interactive elements or create/arrange content themselves

The lowest physical enhancement noted in this sample fell at PE Level 1, in this book the reader moves a visual device which is constrained on a ribbon onto the hole in each page as they read.

Often with this type of book, the content sequencing (intellectual interaction) was also seen to be at the lower end of the continuum, typically a Level 0,1 or 2 . It was also found that often no other interaction types were used with Movable Elements books, two books were found to use questions, one book expressive typography, one book hole in the page and another book used simple counting.

\section{Lift Flaps (a physical interaction type of book)}

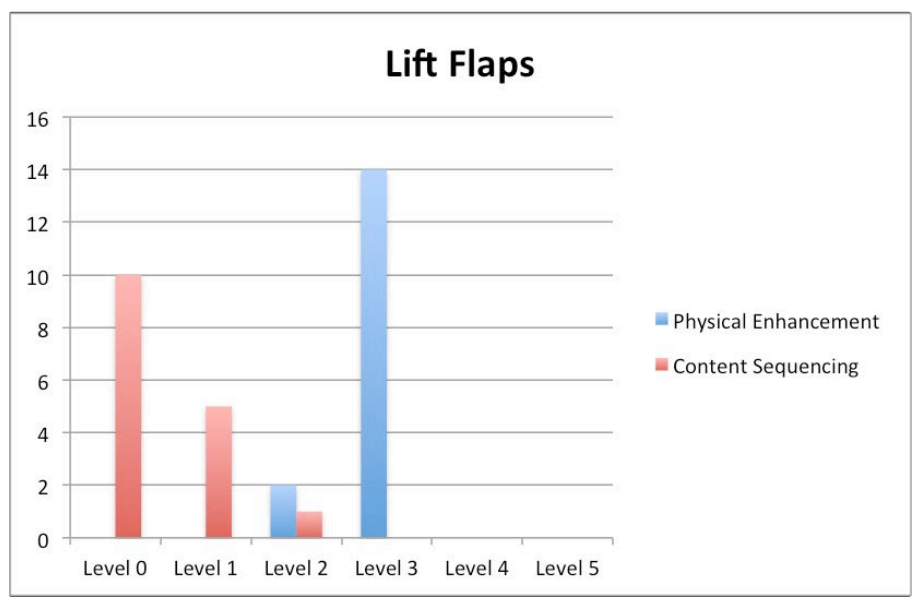

Figure 7: How Lift Flap books were classified according to the Timpany and Vanderschantz method 
In our sample we found 16 Lift Flaps books. These types of books typically fell into the Physical Enhancement scale in the following way:

Level 2 - Reader is required to open additional inner pages to reveal further content

Level 3 - Reader is required to lift flaps, turn wheels, pull tabs, push buttons etc.

Often with this type of book, the content sequencing (intellectual interaction) was seen to be much lower, typically a Level 0,1 or 2 . Books of this type often combined simple counting (2), enhanced illustration (2) and pop-up (3) as well as one example each of explore content, expressive type, hole in page, searching illustration.

\section{Pop-up Books (a physical interaction type of book)}

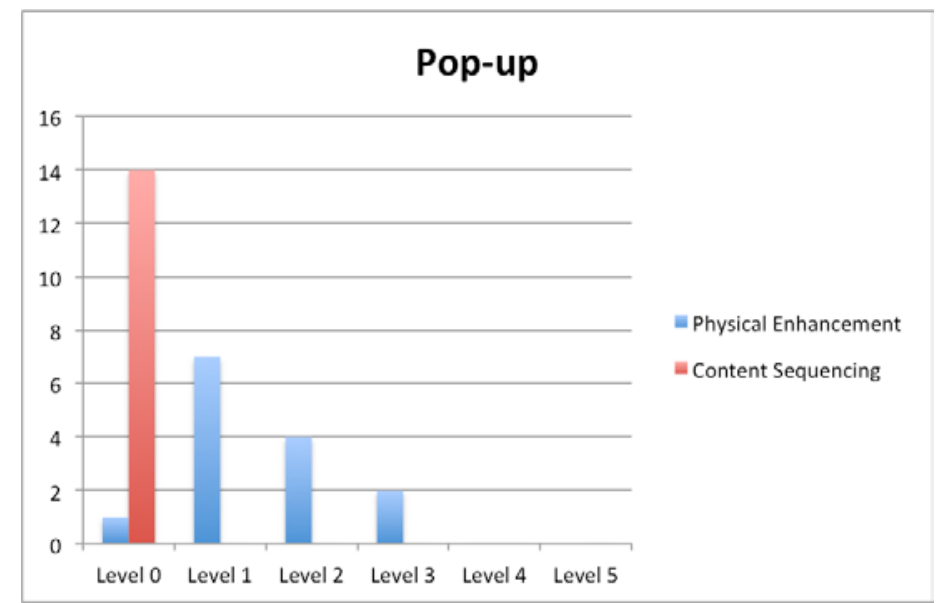

Figure 8: How Pop-up books were classified according to the Timpany and Vanderschantz method

In our sample we found 14 Pop-up books. These types of books typically fell into the Physical Enhancement scale in the following way:

Level 1 - Reader is required to open book and turn pages with some additional interaction with the book

Level 2 - Reader is required to open additional inner pages to reveal further content

Often with this type of book, the content sequencing (intellectual interaction) was seen to be much lower, in this category of book all 14 Pop-up books were seen to be a Level 0 CS. Pure Pop-up books (defined as having pages which cause a sculptural/3D element to emerge from the page surface) are relatively low on the interaction scale as opposed to books which many would deem to be 'pop-up' books which require the reader to lift flaps, turn wheels, pull tabs, push buttons etc. This distinction was made because the reader would typically open/turn pages in the usual course of the act of reading a book, yet adding pull tabs, lifting flaps, turning wheels etc. was interaction in addition to the typical interactions needed to read a book.

Additional interactive features present in this type of book were Lift flaps (3) and one each of enhanced illustration, hole in page, split page, expressive typography. 


\section{Searching Illustration (an intellectual interaction type of book)}

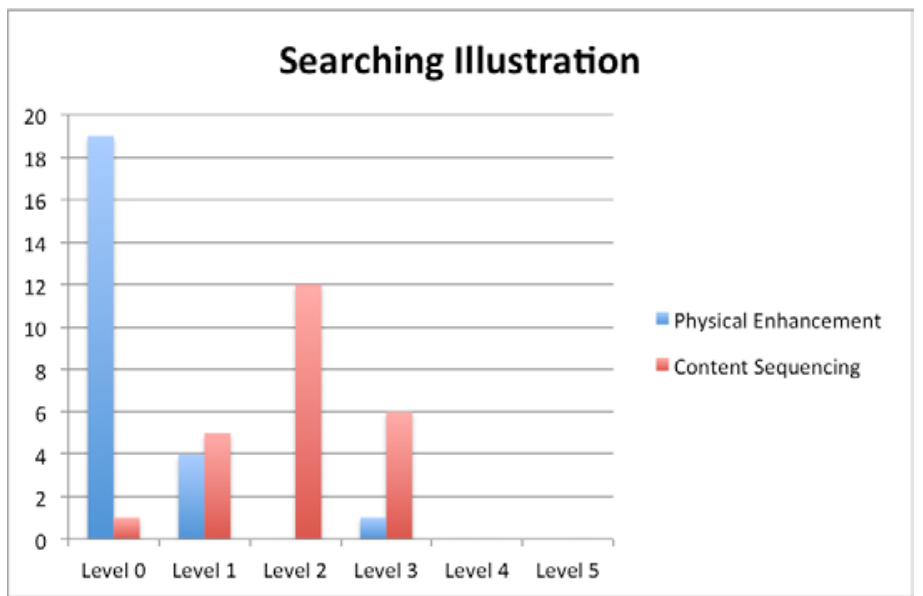

Figure 9: How Searching Illustration books were classified according to the Timpany and Vanderschantz method

In our sample we found 24 Search Illustration books. These types of books typically fell into the Content Sequencing scale in the following way:

Level 1 - Reader's attention is intentionally guided in a non-linear course around page content

Level 2 - Reader's attention is guided in a non-linear course around page/book content and drawn back and forth between set areas of contrasting content

Level 3 - Reader is required to solve puzzles/challenges to/or determine the order in which the pages are read

Often with this type of book, the physical enhancement (physical interaction) was seen to be much lower, typically a Level 0 or 1 . One book also fell into the Level 3 PE category which was a Lift flaps book. Books that urged the reader to search the illustration for objects within it were categorised as either a Level 1 or 2 on the content sequencing continuum, the difference in categorisation was due to the complexity of the searching task that was being encouraged. Often these books also required the reader to solve puzzles (4), or perform activities inside the book (2). One example each of explore content, enhanced illustration, questions and simple counting were also noted within the sample all of which are very low physical enhancements though require varying levels of intellectual engagement.

\section{Activity Books (an intellectual interaction type of book)}

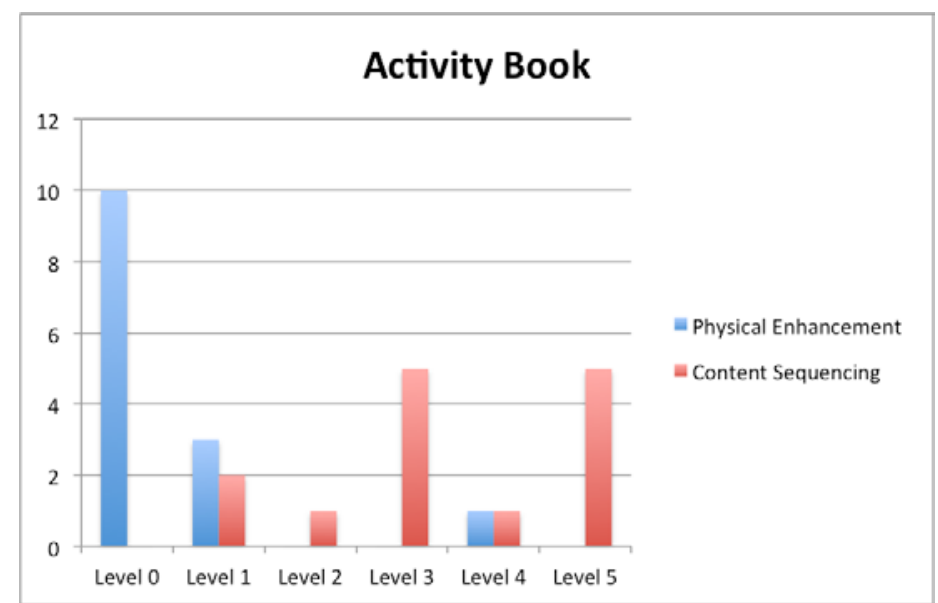

Figure 10: How Activity Books were classified according to the Timpany and Vanderschantz method 
In our sample we found 14 Activity books. These types of books typically fell into the Content Sequencing scale in the following way:

Level 3 - Reader is required to solve puzzles/challenges to/or determine the order in which the pages are read

Level 5 - Reader is required to carry out activities or actions guided by content of the book externally

Often with this type of book, the physical enhancement (physical interaction) was seen to be much lower, typically a Level 0 or 1 . Interestingly, 1 book was also found to be a Level 4 . This book stood out from within this sample of book types as a CS 2 PE 4 because the book included a jigsaw puzzle to complete on every spread, with related images on the facing page, and minimal text. Other types of interactions that were present in Activity books were Explore content (4), Searching illustration (2), Choose story path (2) and Joke books (1).

\section{Explore Content (an intellectual interaction type of book)}

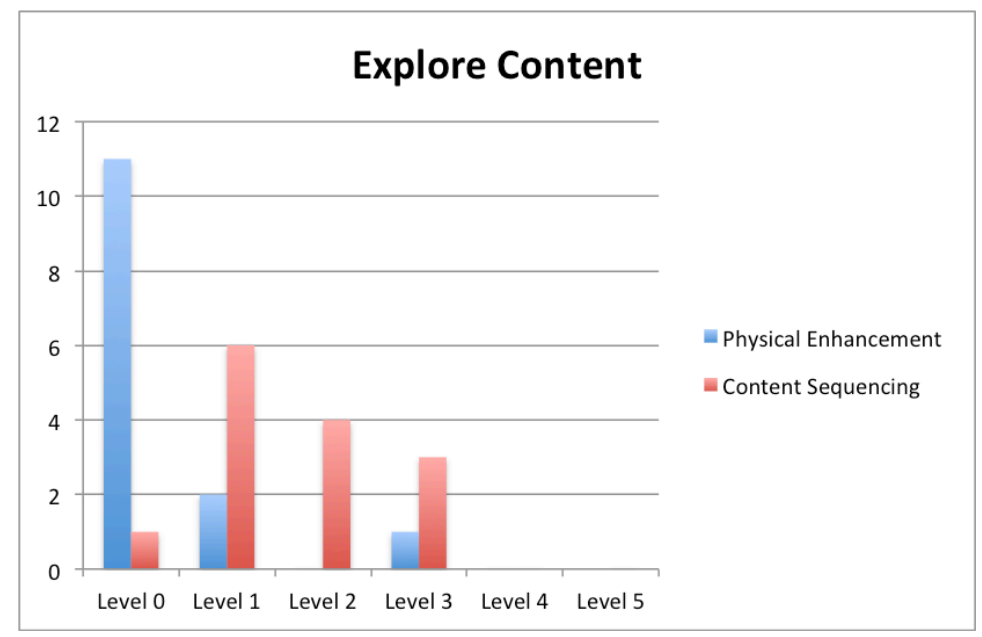

Figure 11: How Explore Content books were classified according to the Timpany and Vanderschantz method

In our sample we found 14 Explore Content books. These types of books typically fell into the Content Sequencing scale in the following way:

Level 1 - Reader's attention is intentionally guided in a non-linear course around page content

Level 2 - Reader's attention is guided in a non-linear course around page/book content and drawn back and forth between set areas of contrasting content

Level 3 - Reader is required to solve puzzles/challenges to/or determine the order in which the pages are read

Often with this type of book, the physical enhancement (physical interaction) was seen to be much lower, typically a Level 0 or 1 . One book was also found to be a level 3 because it also had Lift Flaps physical interactions, which places it at a Level 3 on the Physical Enhancement scale. Books in this sample were books that required readers to explore content and also commonly included activity books (4) or incorporated expressive typography (2). This was often because the content was being explored as part of an activity or the expressive typography helped to instigate the exploration of content.

\section{Conclusion}

This research sought to identify trends in the design of interactions within children's books and how these types of books facilitate both physical and intellectual interactions. In many of the books that were considered linear, or a Level 0 in terms of their Content Sequencing interactivity, 
the interaction occurred at an intellectual level rather than at a physical level and is consequently why the 'curators' of the sampled collections considered them to be part of their 'interactive book' collection. Thus it must be acknowledged that interaction can be either physical or intellectual. While the physical and intellectual interactions enabled by books are interrelated concepts it is useful to separate these two concepts for the purposes of research and investigation. In so doing we will be able to understand the impact that each of these concepts has on reading, learning, enjoyment and motivation for young readers and the effectiveness of each concept in assisting adults to read and experience books with children for added learning opportunities.

The Timpany \& Vanderschantz (2012) classification system offers a mechanism for this evaluation of books through the use of the Physical Enhancement scale which measures the level of potential Physical Interaction, while the Content Sequencing scale considers aspects of potential intellectual interaction and navigation of content.

Books do not tend to incorporate multiple types of interaction as can be seen by the fact that only 35 out of 132 books were shown to do so. It was also evident that books tend to be high on one scale and not the other, except where they incorporate multiple types of interaction. There were however 21 books that created both physical and intellectual interaction in books that employed just one interactive book type. It can be hypothesised that incorporating multiple types of interaction and creating books that are high on both scales will generate new and engaging interactive children's books, but there is also potential for this to be achieved in books that only utilise physical interaction methods or only intellectual interaction methods. Further research in this area is required to understand the effect of levels of interactivity on the way in which a book is used by children and adults and how the levels of interactivity in a book can enhance the reading experience and the learning opportunities present in books. This future research will provide valuable insight to parents and teachers in selecting books for children's learning, as well as for children's motivation to read. This research will also lead to insights for publishers in creating books that serve children, and adults working with children, in positive ways both motivationally and educationally.

Research is currently underway to understand how physical and intellectual interactions and in turn how content sequencing and physical enhancements are used by parents and teachers in shared reading experiences. This is of importance because the way in which an adult facilitates shared reading experiences with very young readers is important for deeper learning and understanding of the concepts of print, the story at hand and the world around the child. Future research is also required to understand how interaction affects children's learning. This is outside the scope of current research, however this system will prove a useful tool for continuing to analyse interaction in children's learning material due to the classification system that has been developed. This system will therefore offer a mechanism for measuring and describing books being studied using a range of methodology and will help to assimilate studies performed by multiple scholars. 


\section{REFERENCES}

Bongers, Bert, and Gerrit C. Veer. 2007. “Towards a Multimodal Interaction Space:

Categorisation and Applications.” Personal Ubiquitous Comput. 11 (8) (December):

609-619. doi:10.1007/s00779-006-0138-8.

Brookshire, Jamye, Lauren F. V. Scharff, and Laurie E. Moses. 2002. "The Influence of Illustrations on Children’s Book Preferences and Comprehension.” Reading Psychology 23 (4): 323-339. doi:10.1080/713775287.

Carter, M. A. 1988. "How Children Choose Books: Implications for Helping Develop Readers." Ohio Reading Teacher 22: 15-21.

Elsom-Cook, M. 2001. Principles of Interactive Multimedia. McGraw-Hill.

Jensen, J.F. 1998. "Interactivity: Tracking a New Concept in Media and Communication Studies." Nordicom Review 12 (1).

Lander, D. 1999. “Online Learning: Ways to Make Tasks Interactive.” UltiBASE, Http://ultibase. Rmit. Edu. au/Articles/lander2. Htm.

Marshall, Catherine C, and Sara Bly. 2005. "Turning the Page on Navigation.” In Proceedings of the 5th ACM/IEEE-CS Joint Conference on Digital Libraries, 225-234. JCDL '05. New York, NY, USA: ACM. http://doi.acm.org.ezproxy.waikato.ac.nz/10.1145/1065385.1065438.

Nodelman, Perry. 1990. Words About Pictures: The Narrative Art of Children's Picture Books. London: University of Georgia Press.

Phinney, Thomas, and Lesley Colabucci. 2010. "The Best Font for the Job.” Children \& Libraries: The Journal of the Association for Library Service to Children 8 (3): 17-26.

Schallert, D. L. 1980. "The Role of Illustrations in Reading Comprehension.” Theoretical Issues in Reading Comprehension: 503-524.

Sims, R. 1994. "Seven Levels of Interactivity: Implications for the Development of Multimedia Education and Training." In Proceedings of the Asia Pacific Information Technology in Training and Education (APITITE) Conference, 3:589-594.

Spence, Robert. 2007. Information Visualization: Design for Interaction (2nd Edition). Prentice Hall.

Thiessen, M., and M. C. Dyson. 2009. “Typography for Children with Reading Difficulties: Preferences for Type in Reading Books.” International Journal of the Book 6 (2): 115122.

Timpany, C., and N. Vanderschantz. 2012. “A Categorisation Structure for Interactive Children’s Books.” International Journal of the Book 9 (4): pp.97-110.

Watts, L., J. D Nisbet, National Foundation for Educational Research in England, and Wales. 1974. Legibility in Children's Books: a Review of Research. NFER.

\section{ABOUT THE AUTHORS}

Claire Timpany: Claire completed her Masters in computer graphic design at Wanganui School of Design, New Zealand. She is currently a lecturer in computer graphic design at the University of Waikato, New Zealand, teaching both print and screen-based papers. Her main areas of interest and research are typography, print design and physical interaction design. Because of her love for both printed books and interactivity, this is where her research interests lie. Her research is currently focused on the way in which people interact with printed material and how the benefits of electronic media can be applied to traditional media, such as print, to aid it in developing and become more beneficial and keeping up with the digital age.

Nicholas Vanderschantz: Nicholas' area of research focus has been in childrens' on screen reading. These investigations have specifically looked into how typographic spacing could best affect childrens' eye movements during reading. This area of exploration saw him graduate with 
a Masters in computer graphic design from Whanganui School of Design, New Zealand in 2007. $\mathrm{He}$ is a lecturer in computer graphic design at the University of Waikato in New Zealand. As a central part of his teaching and research at the University of Waikato, he pursues his interests in typography for children as well as socially responsible graphic design and graphic design education. 